\title{
A Diletto and his Storytellig Strategy
}

\author{
Rachel Farias do Patrocínio
}

\author{
Rafael Figueiredo
}

\author{
Juliana Lopes de Almeida Souza
}

\begin{abstract}
The strategy of involving consumers and prospects through tales or stories in advertising, known as storytelling, has been widely used by organizations and well accepted by the general public. One of the companies that bet on this format was the brazillian ice cream and popsicle maker, the Diletto brand. However, the strategy of storytelling used by the organization had a negative repercussion, because the story told was not exactly the real story about the beginning of the company. Thus, this article intends to identify the true reasons that made Diletto's strategy detrimental to the brand. To that end, the paper tackled how a non-assertive storytelling strategy can compromise the organization's image. The research identified, through data collection research and the theoretical basis of authors who are specialists in the subject, the factors that led to the failure of the strategy and why the negative repercussion involving the brand, after the true story became public knowledge.
\end{abstract}

Keywords: Storytelling; Branding; Diletto.

\section{INTRODUCTION}

As we can see in media planning, advertising uses a variety of strategies to capture the public's attention and promote products and brands. One of the strategies used is storytelling, which consists of telling stories. Several brands have already used this feature in their way of communicating, but not all have obtained a satisfactory result. The present work uses as an object of study the brazillian brand of premium ice creams and popsicles Diletto, one of the companies that uses storytelling as a communication strategy in the world of advertising. The organization is of Brazilian origin and was founded in 2008, achieving a turnover of approximately 13 million dollars each year (LEAL, 2014).

The company was chosen to be the object of this study because of the history of the brand presented to the public, which was untrue, even though it was present on the company's website and packaging of the products until the year 2014. According to the narrative, the Diletto company began with Mr. Vittorio Scabin, an Italian who was dedicated to a craftwork production of popsicle, with mixture of fresh fruits and snow. With the arrival of the Second War, Mr. Vittorio took refuge in Brazil. Then, almost a century later, his grandchildren continued his work with the same passion, perfectionism and dedication of the grandfather. Thus, the ingredients are carefully chosen by them, such as the pistachio coming from Sicily and the raspberries harvested in Patagonia (Annex 1). However, as mentioned above, the story told by the company is not true. It was created as a marketing strategy to promote the brand and add value to its products. With this, some consumers, after reading a report of a prestigious business publication in Brazil, Exame magazine, written by Ana Luiza Leal in 2014, found that the story was not true, felt cheated and filed a complaint in CONAR (Brazilian legislation agency for the advertising business). For its part, the regulatory body recommended, in representation No. 263/14, that the mark altered the history present on the packaging and on the website, including the withdrawal of the citations from Mr. Vittorio and 
his relation with the manufacture of the Diletto ice cream. Thus, this paper aims to identify the points that led to the failure of the strategy and the negative impacts on the Diletto brand. To guide the study carried out in this article, it was firstly defined the theme of the work: communication strategies using the technique of storytelling and the impact on the credibility of the company.

The justification for choosing this theme is the fact that storytelling is constantly being used by advertising agencies and professionals as a means of capturing the public's attention and engendering more engagement with the brand. However, using this strategy inefficiently can be disastrous and have negative impact on organizations. Thus, the present work is a case study about the Diletto brand and the consequence of the strategy used to promote its products, and the main research problem is to identify why, among so many advertising messages that use stories, Diletto's Was harmful to its brand? To answer the question, it was defined as the general goal of the work to address how the storytelling conducted by Diletto, in a non-assertive way, undermined the brand's brand equity. Also, two specific objectives were defined, the first one being to identify the main factors that led to the failure of Diletto's communication strategy using storytellig and the second to show how Diletto's storytelling strategy negatively impacted the brand.

\section{Branding: the value for a brand}

According to Pinho (1996), the American Marketing Association (AMA) definitions committee defines a brand as a name, term, sign, symbol or design, or a combination of these items, in order to identify goods or services of a seller or group and differentiate them from the competition. In this way, we perceive that a brand is defined by a set of visual aspects that label what we intend to deliver to the consumer. However, it is not just these elements that represent the true strength of a brand. It may be responsible for providing a host of consumer experiences by arousing good and bad feelings about it. With this, the public that relates to the brand starts to base its decision of consumption on these sensations. The consumer will then be willing to pay more for a particular product and defend the company in any situation, or will be disgusted with it, avoiding to acquire any product / service connected with it and inducing other people to have the same behavior. Thus, we see that there is a perception of the value of the brand by the consumer.

The brand represents a true value system, relatively simple in many cases and highly complex in others, capable of defining - and even magnifying considerably - the value limits of each product, service, company, institution or even, person. In conclusion, it can be said that the brand is the synthesis of the experience of value lived by the consumers in relation to each of the numerous products, services, companies, institutions or even people with whom they relate (Sampaio, 2002, p. 25).

We can see that consumers relate to brands through their experiences with them. But the stakeholders of a brand are not only composed of the public that purchases its products or services. There is also the relationship that a brand creates with other companies and institutions, competitors or not. This relationship is also driven by feelings and experiences, however, brands can also add financial value to organizations. The more a brand is viewed and perceived positively by the market, the greater the chances of being a reference in a certain subject, product or service and, with that, increase its billing. After all, "the brand is, for organizations, the synthesis of the market-value value of its products and services, as well as of the companies and institutions themselves, and even of people as products" (SAMPAIO, 2002, p.26 ). Thus, we can perceive the brand as one of the main assets of a company, being 
fundamental for the organization to watch over it and to use strategies so that it is increasingly perceived by the market. For, as defined by Aaker (1996), the value of a brand is the set of assets and liabilities linked to the brand name and symbol, which add or subtract value to a product or service of a company and / or its customers.

The consideration of brands as organizational assets, as explained by Sampaio (2002), it is necessary to watch over them and make them stronger in the market. In this way, it is necessary to think and define strategies that contribute to their positive perception by their target audience. It is important to know that they need to be managed by competent professionals who work with efficient and effective marketing strategies to ensure that the brand image is aligned with the organization's objectives.

Thus, we arrive at the simplified definition of branding as "the set of marketing tasks including its communication tools - aimed at optimizing brand management" (SAMPAIO, 2002, p.27). We can also observe the more in-depth definition that Kotler (2000) brings us about the term:

Branding means endowing products and services with the power of a brand. It is all about creating differences. In order to put a mark on a product, it is necessary to teach consumers "who" is the product [...] as well as "what" it is intended and "why" the consumer should be interested in it. Brading is about creating mental structures and helping the consumer to organize their knowledge about products and services, so that their decision-making becomes more enlightened and, in this process, generates value to the company (KOTLER, 2000, p.269).

Therefore, branding plays an important role in narrowing the public's relationship with the brand by creating strategies for them to provide positive experiences to consumers, since, according to Kotler and Armstrong (2007), brands represent the perceptions and feelings of Consumers in relation to a product and its performance, everything that the product or service means to consumers. In addition, we live in a market scenario with increasingly fierce competition. Therefore, as Kashani (1996) argues, consumers are more informed and more skeptical of false or non-coherent promotional appeal ads, and are even more eclectic due to the diversity of products offered in the market, especially with the ease of internet access nowadays.

It is through branding that the public will be captivated and will establish a perception of brand value. Consumers will be willing to acquire products of a particular brand more easily and even pay more for its product or service than those offered by the competition. This type of value can be called added-value.

Aggregate values are psychological; They exist in the minds of consumers. [...] These aggregate values originate from consumers' experiences regarding the brand, the types of people who use them, the buyer's confidence in brand effectiveness, and the brand's appearance (JONES, 2004, P. 385)

For Kotler (2010), building customer value is the best way to relate to it and achieve profitable results, not just financial but lasting relationships. In this regard, branding will help to make unique the experience in acquiring the product / service, meeting the expectations of the customer and their needs.

\section{Brand Equity: the perception of value for consumers}

The perception of brand value by customers can also be defined by another name: brand 
equity. While branding is defined by Sampaio (2002) as the set of marketing tasks aimed at optimizing brand management, brand equity is understood by Aaker (1998) as the set of assets and liabilities linked to a brand, its name, or Symbol, which add up to or subtract from the value provided by a product or service to a company or its consumers. Kotler and Armstrong (2007), on the other hand, use a more succinct definition that brand equity is the positive differentiating effect that brand awareness has on the customer's reaction to the product or service. In this way, we can observe that all branding strategies of a company aim to increase its brand equity. For, the greater the brand equity, the more the organization can stand out in the market and occupy the top of products that are reference in the market. Big companies, like Disney and Coca Cola, are examples of companies with high brand equity. They become true market icons and maintain the loyalty of their consumers for generations.

In order to measure brand equity, companies must pay attention to four items, as presented by Nunes and Haigh (2003): brand recognition, when the consumer is able to identify it; Fidelity, central point of value; Quality, which allows the consumer to realize the return on investment made; And association, which connects the consumer to the brand, being able to be through images, attributes, situations, symbols, etc. This measurement can be performed with marketing research aimed at identifying each item that makes up brand equity. It is important to realize that brand equity provides value not only to the consumer, but to the company. After all, Drucker (2000) states that it is the consumer who determines what a company is, because what he believes to be buying, what he considers "value" determines what a company is, what is produced, and what will prosper or not. For him, the customer is an ally and always comes first. So, we can affirm until now that every company needs a brand that differs from other competitors and needs marketing strategies, called branding, to make it increasingly perceived by the market and increase the value perceived by consumers, that is , The brand equity.

\section{Storytelling: An Advertising Strategy}

One of the strategies used by some brands to differentiate themselves from the competition and further captivate the audience is storytelling. But to understand more about this concept and how it has contributed to leverage the brand equity of some organizations, we need to delve a bit more into the subject. The act of telling a story, or telling a fact, has already existed since the beginning of time. According to Motta (2004), the narrative consists of a universal, transhistorical, pancultural practice and, according to the author, all peoples, cultures, nations and civilizations have been constructed narrating. Thus we perceive the importance of narrative for human beings, for this act is realized even before language.

This strategy has been constantly used by art, whether through literature or film productions. However, advertising has already realized the power that stories have in the consumer's mind, after all, stories are capable of holding the audience's attention. In this sense, according to Palacios and Terenzzo (2016), managing this attention will be a determining factor for many companies. Those who do not learn to attract the attention of their audience through stories may be out of the market. This is because the consumer is impacted by several advertising messages daily and still shares his attention with the posts of friends carried out on social networks. In this way, the term storytelling has been used when stories have an advertising appeal and are aimed at promoting brands.

Broadly speaking, all narratives are storytelling; So narrowly, would only storytelling the narratives constructed to be used with the blunt intention of formatting thoughts. In the media, they become products for sale, while in marketing they are used as a means of persuading and 
creating habits of action; In advertising, the history of an anthropomorphized product as a character capable of satisfying needs (DOMINGOS, 2008, p.01).

Thus, we note that, when impacted by a storytelling strategy, the consumer does not acquire the product or service solely because of its usefulness or brand, but because it relates emotionally to that story. Reinforcing this statement, we can also say that "people do not buy products, but the stories that these products represent" (RAMZY, 2002, apud: MATOS, 2010, p.13). The commotion of individuals by stories may be related to identification with life itself. All people have gone through moments that made them feel sad, joyful and other emotions. So when we are introduced to a story, we can imagine ourselves as the characters and put ourselves in their place, that is, we go through a process of projection, in which the choices and destinies of the characters of the story impact us strongly, Situations as if we were passing through them.

Storytelling is the simulation of a reality. By captivating attention, the narrative causes an immersion that reaches the sensory level. [...] The person who is attentive jumps into a character, sometimes cheering for him and sometimes putting himself or herself in his place. Whenever we are attentive to a story we share the look and feelings of the characters. For the good or for the bad. We vibrated together, but we also wept in tune. When something is very important to the protagonist, it becomes very important for those who are aware (PALACIOS and TERENZZO, 2016, pp. 103-104).

Generally, stories can be told in two ways: real facts or fictitious situations. Both forms can be used as marketing and advertising strategies. When storytelling strategies use real facts, they are constructed from an individual's access to memory, using it as a tool of "building the past, but based on emotions and experiences, it is flexible and events are reminded of the Light of subsequent experience and the needs of the present "(FERREIRA, 2002, p.321), that is, narratives are constructed from the experiences the individual has passed through or from reports he has heard from others who have passed through certain events. Generally, this way of applying storytelling is well used for organizational communication, where the stories of employees or the organization itself can be presented to the public. Thus, "the company itself is anthropomorphized as a character that also has a story to tell, as well as the products that it ends up generating and offering to the consumer public" (DOMINGOS, 2008, p.2).

Storytelling strategies that use fictitious situations are not retained to the memories to construct the narrative. In this case, the use of imagination is fundamental to reproduce the story that will be told, using even elements that flee from known reality, with the creation of something new, of a new reality. This, according to Llosa (2004), because the human being is not happy with his destiny and almost everyone would like to have a life different from the one that they live. Fiction has come to heal this desire.

Moreover, in the case of strategies favoring brand equity of brands, it is important to establish a reality whose events make sense to the public, but are extraordinary in their executions.

It is necessary to have conditions of verisimilitude and veracity that ensure communication with the reality lived, that the characters participate in some part of the daily humanity, but it is also necessary that the imaginary rises a few steps above the daily life, that the characters live with more intensity, more love, more affective richness than the common of mortals. It is also necessary that imaginary situations correspond to deep interests, that the problems dealt closely with the needs and aspirations of readers or spectators (Morin, 2009, p. 82-83). 
However, depending on how the story is conveyed by the organization, the difference between reality and fiction may not be perceived by the audience, at the risk of making them feel cheated. Thus, we can interpret that, like any advertising message, storytelling also needs to be built within ethical standards.

\section{Ethics in Advertising: values in a society}

Understanding the fundamental values that must be worked out by advertising in communication actions, it is important to establish a concept we understand as ethics. Every group of individuals is governed by a set of norms that regulate their behavior so that they coexist well in a society. According to Ferreira (2005), these norms and principles of conviviality are what we call ethics. Because it is a set of social behaviors, we realize that it will always be collective, taking into account the group in which it is inserted. Reinforcing this principle, we can still say that "there is no individual ethics. Ethics is always a group, a collectivity "(CORTELLA, 2013, page 51). In this way, we realize that in order for there to be a good coexistence between the individuals of the same society, they must act in accordance with ethics. So, for an advertising message to be well accepted by the public, it also needs to obey these social rules. To ensure that this happens, there is CONAR (National Council for SelfRegulation Advertising), which acts in response to complaints from consumers, authorities and associates, so that Brazilian advertising is always within the standards considered ethical by the social system.

According to the CONAR website, the basic precepts that defend advertising ethics are: every advertisement must be honest and true and respect the laws of the country (Brazil in this case); Should be prepared with the proper sense of social responsibility, avoiding accentuating social differentiations; Must bear in mind the responsibility of the production chain with the consumer; Must respect the principle of fair competition; Should respect the advertising activity and not detract from the public's trust in the services that advertising provides. However, the responsibility of providing ethical advertising content to the public is not from CONAR, but from the organizations themselves. Particularly with regard to the relationship between brands and their consumers, since, as Murta (2007) affirms, advertising must be effective, persuasive and informative, and should always contribute to consumer confidence. The author further emphasizes that the public has much confidence in what is said by advertising, but that there is no need for the message to be totally explicit.

Throughout the communication process, the receivers assume that they will not be cheated, will not be offended or will not suffer loss of any kind derived from the messages. The veracity of the communication does not imply that the information has to be absolutely accurate. [...] On some occasions, a certain margin of maneuver can be admitted, a certain "publicity license" regarding the absolute truth, without abandoning the veracity of information (MURTA, 2007, 32).

In conclusion, it can be observed that, although advertising campaigns can modify reality a little, in making what is portraited more attractive, it is fundamental that the public be informed with the truth. The company, through advertising actions, must respect the trust that the consumer places in the transmitted messages.

\section{Methodological procedures}

According to Cervo, Bervian and Silva (2007), all research is a form of investigation of theoretical or practical problems, using scientific processes. According to these authors, any research aims to find an answer to a given problem. In this article, we sought to identify why 
the storytelling strategy used by the Diletto brand was detrimental to the brand, and other companies that adopted this strategy were successful. This work used research and data collection methods to be developed. As stated by Gil (2008), before starting a research it is necessary to define the objective and to categorize it as: exploratory, descriptive and explanatory.

According to Gil (2008), the exploratory research happens when one has to become more familiar with the subject, making it more evident or constructing hypotheses. It can be done with bibliographic consultation, interviews and, almost always, takes the form of a case study. Therefore, in this article, the exploratory research method was used because it aims to raise more information about the communicational technique of storytelling and to better understand why the strategy adopted by Diletto generated a negative repercussion for the brand. Thus, we move on to a second moment, in which Gil (2008) states that it is necessary to define the forms of data collection used to respond to the problem chosen to be object of the research.

One of the methods used was the bibliographic research. For Vergara (2000), this type of research is developed using already existing material, composed, for the most part, of books and scientific articles. Lakatos and Marconi (2001) also reinforce the contents that can be used for data collection, as well as their purpose.

[...] includes all bibliography already made public in relation to the subject studied, from single publications, newsletters, journals, magazines, books, researches, monographs, theses, cartographic materials, etc. [...] and its purpose is to put the researcher in direct contact with everything that has been written, said or filmed on a certain subject ... (LAKATOS and MARCONI, 2001, 183).

Thus, there were consultations to various scientific articles and books to compose the theoretical foundation of this article, as well as searches in these same materials and in news sites on the internet about the strategy of storytelling adopted by Diletto. Another form of data collection used was the survey survey. According to Gil (2008), this model has the main objective of directly interrogating a group of people about a certain subject, with the use of a questionnaire. In this way, it is possible to identify the behavior of the respondent group, because, through the information obtained, a quantitative analysis of the generated data is made and a pattern can be identified. Other authors conceptualize this form of collection only as quantitative research. One of them is Richardson (1999), who defines it by the characterization of the quantification, both when collecting information, and when it is time to analyse the data using statistical techniques.

Thus, to carry out this research, an online questionnaire was carried out through the Google Forms platform, applied via social network: Facebook. The survey was available from April 29, 2017 until May 12, 2017, obtaining 201 responses. The questionnaire sought to collect statistical data about the public perception of storytelling strategies used by companies and, especially, regarding the case involving Diletto. The questions asked are available in this paper (appendix 3). In addition, another form was also used for data collection, the case study, once the company Diletto was researched. This format is defined by Yin (2001) as follows:

A case study is an empirical investigation that investigates a contemporary phenomenon within its real-life context, especially when the boundaries between phenomenon and context are not clearly defined [...] The case study research faces a situation technically The only one in which there will be many more variables of interest than data points, and as a result, is based on several sources of evidence [...] 
(YIN, 2001, p.

Thus, it is perceived that a deeper analysis of the object of study is necessary, since it was not clear why the Diletto brand had gained a negative image after the repercussion of the case involving the strategy of storytelling. So, with the objective of collecting the public's perceptions about the subject in question and obtaining qualitative data on the subject, a focal group involving 6 different people, with an average duration of 30 minutes, was held on May 10,2017 . The script that guided this process is available in appendix 1 of this article. In this technique, the group is led by a mediator to discuss the subject being addressed. Generally, this format allows more freedom of expression, which encourages the participation of the group members. Regarding the importance of this technique, Gatti $(2005$, p.9) says that "there is interest not only in what people think and express, but also in how they think and why they think".

Participants were able to tell about their relationship with the Diletto brand and express their views on the strategy used and the way in which they were impacted. The focus group was filmed and the link is available in the appendix to this paper (appendix 2).

\section{DATA ANALYSIS}

First, we analyzed the information collected through the survey, which provided quantitative data about the theme proposed in this study. However, first of all, it is necessary to identify the participants' profile regarding schooling, age and monthly income.

\section{Figure 1 - Schooling}

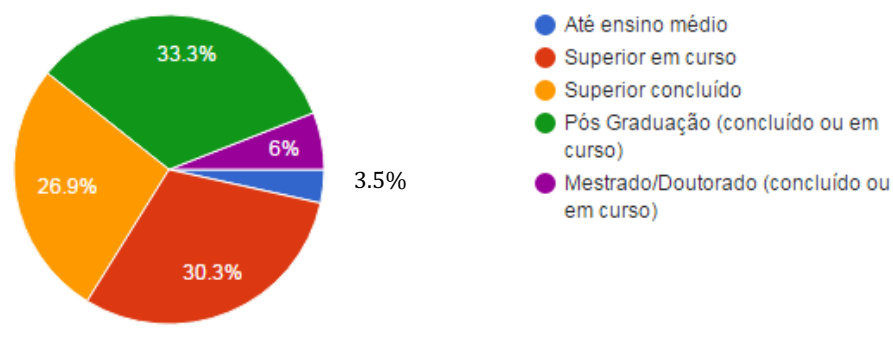

Source: Google Docs search result

Regarding schooling, we can see in the figure above (figure 1) that the vast majority of respondents have a degree in some academic area, which represents $66.2 \%$ of the participants. Among the others, we have more than $30 \%$ of respondents attending a higher education course. This shows that, in general, the participants have a good academic background.

Figure 2 - Age
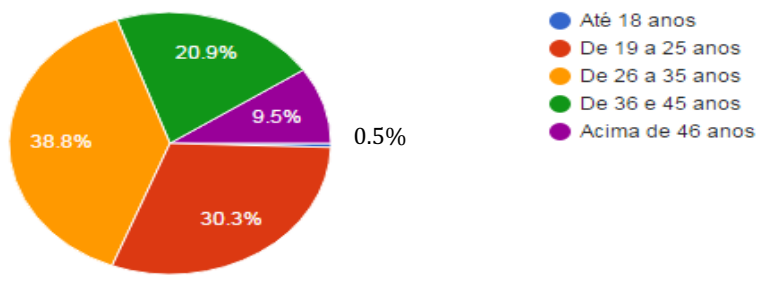

Source: Google Docs search result 
Regarding the respondents' age (figure 2), we can observe that practically all respondents are over the age of 18, most of whom are between 26 and 25 years old. This shows that the majority of the audience is mature enough to understand the questions and the subject matter.

Figure 3 - Monthly income

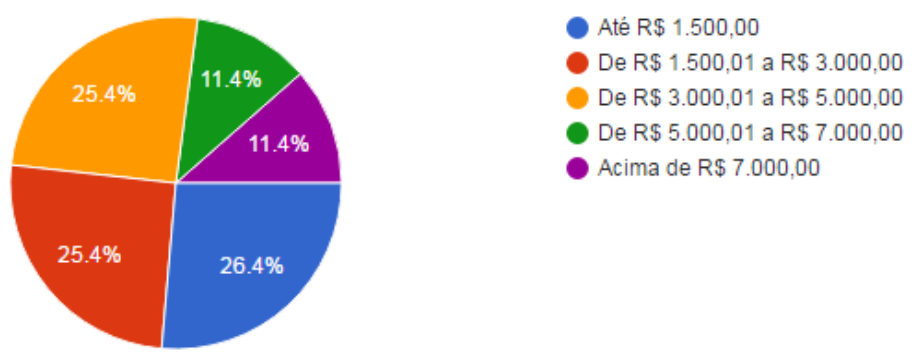

\section{Source: Google Docs search result}

Now, on the monthly income of the participants (figure 3), it is clear that there are very diversified purchasing power between them. Statistically, the majority (26.4\%) earns up to 1,500 dollars. However, practically the same amount of people earn between 1,500 to 3,000 $(25,4 \%)$ and between 3,000 to $5,000(25,4 \%)$.

Then, the participants' answers about their perception of storytelling strategies in general, focusing on the Diletto brand case, are analyzed.

Figure 4 - Do you like when brands tell stories to promote your products?

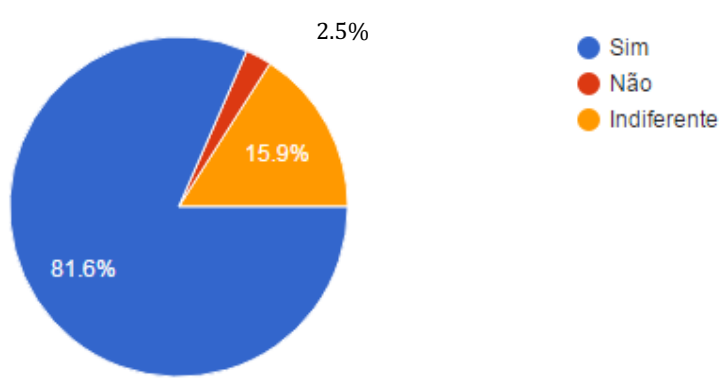

\section{Source: Google Docs search result}

It was asked whether participants like when brands use stories to promote their products. As we can see in the graph (figure 4), most (81.6\%) like this strategy, while $15.9 \%$ of the respondents are indifferent to this communication format. This data reinforces the power that storytelling strategies have for attracting audiences. 
Figure 5 - Do You believe storytelling strategy can bring the brand closer to the consumer?

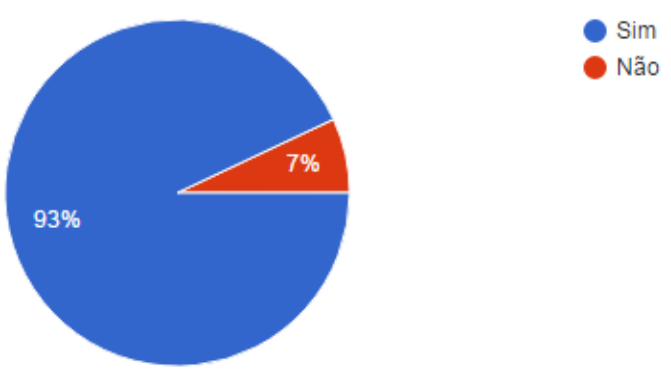

\section{Source: Google Docs search result}

When asked if the storytelling strategy, from the point of view of the participants, can bring the brand closer to the consumer, most (93\%) said yes (figure 5). This strengthens the idea that stories can be used in branding strategies and contribute to brand equity.

Figure 6 - Do you consume or have already consumed Diletto brand ice cream and popsicles?

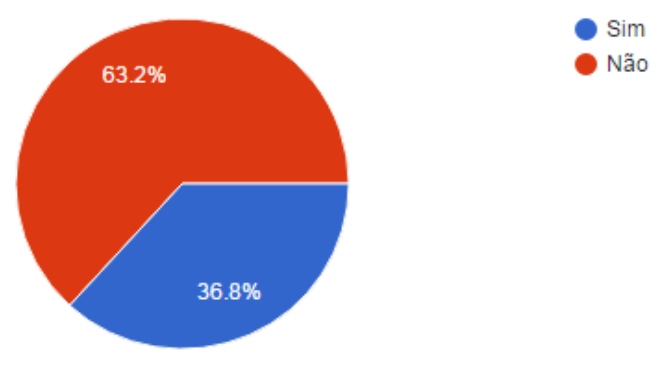

\section{Source: Google Docs search result}

To identify whether the research participants were Diletto consumers, they were asked if they had already consumed any of the brand's products. Among the responses (Figure 6), 63.2\% said they had never consumed popsicles or ice creams. This shows that the product is not as popular among the attending audience.

Figure 7 - On average, how often do you consume this brand's products?

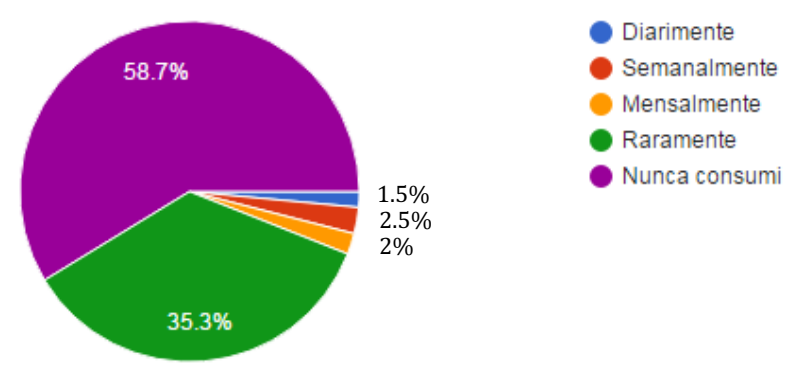

\section{Source: Google Docs search result}

In addition, it was asked about the periodicity of consumption and the majority of participants who had already consumed Diletto claims to consume rarely (35.3\%), as shown in figure 7. 
There were also participants who said they consumed the products more frequently, however, there were few, Totaling 6\%. We perceive, then, that the brand is not consumed frequently by the respondents, possibly because it is a product that reaches a higher social class.

Figure 8 - Do you know the story Diletto told about the brand?

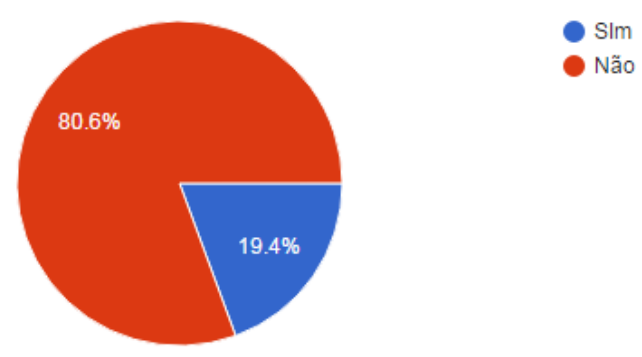

\section{Source: Google Docs search result}

Still on the Diletto brand, it was asked if the participants know the story that was told by the brand about its history. As shown in Figure 8, most did not know (80.6\%), probably because they did not have a relationship so close to the brand. After this question, the story was presented to continue the questionnaire.

\section{Figure 9 - You felt cheated to find out that the history of the brand was it not true?}

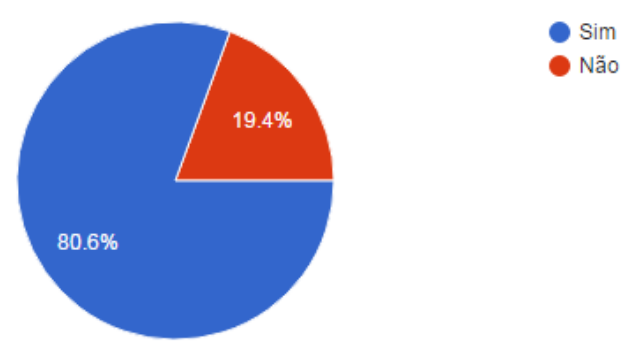

\section{Source: Google Docs search result}

After learning the story, respondents were asked if they felt cheated when they discovered that the story told by the company was not true. The majority (80.6\%) said yes, as Figure 9 shows. This data demonstrates that participants, even believing that stories approach consumer brands, condemn the use of Diletto's strategy. In addition, the data reinforces the importance of ethics in advertising, in agreement with Murta (2007), in that the author says that the consumer has much confidence in what is said by the publicity. 
Figure 10 - The story told has influenced or will influence the way you do you consume the products or see the brand?

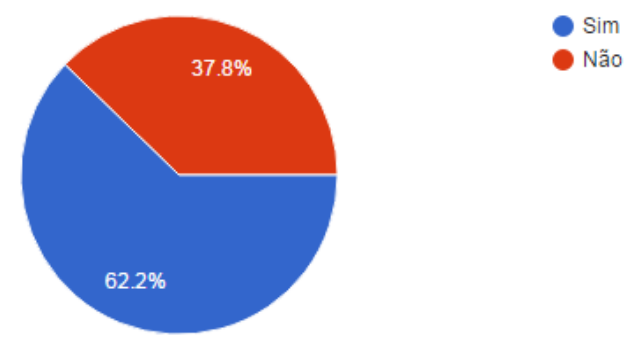

\section{Source: Google Docs search result}

It was also asked whether there will be a change in the way the brand is consumed after discovering the truth about Diletto's history. Most of the respondents (62.2\%) said yes, as can be seen in figure 10. What once again points out that stories have the power to influence the brand equity of a brand.

Figure 11 - Even though the story is not true, you continued or will you continue to buy branded products?

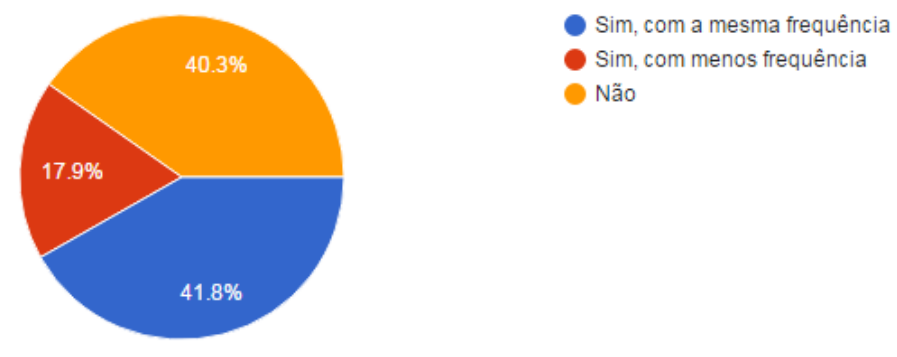

\section{Source: Google Docs search result}

It is interesting to observe in figure 11 that, although the participants stated that they felt they were mistaken for Diletto's history and that they would change their way of consumption, a large part of the respondents (41.8\%) stated that they will continue to acquire the product with the same frequency. Since many respondents were not consumers of the brand, it can be considered that they will remain without interest in Diletto products. Another point that can be observed is the number of people who said they did not consume the products after knowing the truth $(40,3 \%)$ or that they will consume less frequently $(17,9 \%)$. This indicates that the brand history strategy had a strong impact on the public, to the point of making them choose to lose interest in the brand's products. 
Figure 12 - In your perception, the brand lost credibility after telling this story?

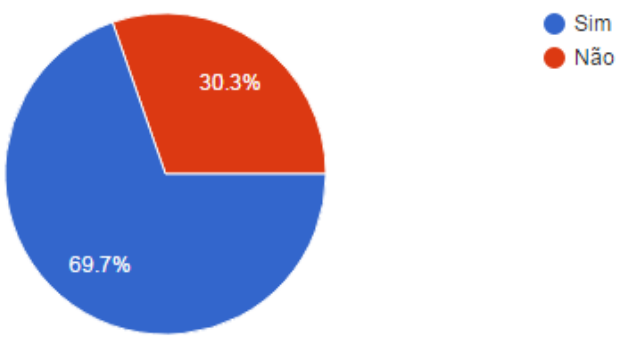

\section{Source: Google Docs search result}

To close the questionnaire, it was asked whether the brand lost credibility after using an untrue story in its strategy. In the perception of the majority of participants (69.7\%), as shown in figure 12, Diletto had its credibility shaken by its strategy. This information reinforces the idea that the use of storytelling by the company was not assertive, from the point of view of communication, besides negatively impacting the brand.

\section{Focus group analysis}

At this point, the information obtained through the focus group is analyzed. This method allowed to gather quantitative data on the object of study of this work and to identify the experiences and perceptions of the participants in relation to the strategies of storytelling and the case involving Diletto. During the process, participants stated that they are influenced by brand advertising that conveys credibility to the consumer. Often, according to them, the credibility is related to the indication of others who have already consumed the product or who believe in the values of the brand. In fact, we realize how much the advertisements influence the audience when one of the participants says that "if it is on television is good". In this way, we perceive the importance of working with branding strategies so that the brand is always perceived positively by the consumer. As participants begin to be encouraged to talk about their perception of storytelling strategies, one of them states that they are interested in knowing stories of brands, especially those of success, such as Coca Cola. However, it states that

Knowing the history of the brand is not a guarantee that it will consume the products of the company, but if the story has any relation to their people beliefs, it will be a factor that could stimulate consumption.

Most participants prefer when storytelling strategies of companies use fictitious narratives to encourage consumption, believing it to be more attractive. The Catuaba brand is mentioned as an example, for having created a totally fanciful story to announce a new flavor of its products and, according to the testimony of one of the members of the group that is a frequent consumer of the brand, the strategy was a success. This data reinforces the acceptance of storytelling by the public and shows how it can be a good brand equity strategy.

Regarding the veracity of the stories told by the brands, the group agrees that the general public would not fail to consume a certain brand if it discovered that some brands may not be true, but affirm that the company responsible would lose credibility. Once again, Coca Cola was cited as an example and the fictitious hypothesis of its history not being true was raised. One participant says that "if she lies about the story, imagine what she has in that bottle." In addition, another participant claims that he would stop consuming the product if he discovered that a story told is not real. When we started talking about the object of study, Diletto, most of 
the participants knew the brand, but were not frequent consumers. In order for everyone to be aware of the case, the whole history of the brand was presented by the company and, after that, the true story was revealed. One of the participants stated that they would no longer consume branded products after discovering the truth and others would continue to buy as long as there was no change in product composition regardless of whether the story was true or not.

The group concluded that Diletto used a number of elements that addressed consumers' emotional issues, such as reporting that the owner's grandfather took refuge in Brazil during World War II. According to them, there was no need to tell a false story to sell the product, as this would not stimulate the purchase. One of them said that he started to consume the product only by the design of the packaging and the format of the point of sale.

In addition, one of the participants who felt cheated to discover the truth about Diletto's story said that the brand "used a strategy of lying to strengthen itself, for the product sold to be more expensive. In my opinion, this is cheating the consumer. I do not think that's cool. [...] A marketing strategy cannot be based on a lie. "This report shows how Diletto's strategy was perceived as unethical.

Because, as we already talked about what is said by Murta (2007), the public believes in advertising and will not be deceived by it.

To finalize the focus group, participants agreed that if Diletto had chosen to work on the storytelling strategy using a fictional story, which was absurdly fantastic, it would be much more assertive. After all, according to them, people would know that this was not a real story. With this, we can observe that, in order to be used, storytelling needs to make clear to the public what is real and what is fiction, thus respecting the consumer.

\section{Final considerations}

It seems that the human being is really involved in narratives and gives more attention to the advertising that uses storytelling as a marketing and communication strategy. After the data collection carried out by the surveys, it was noticed that the strategy of storytelling conducted by Diletto, in a non-assertive way, undermined the brand's brand equity. After all, it was possible to obtain quantitative and qualitative data that proved the admiration of the public in relation to storytelling, but criticize the way in which the company used this strategy, considering it unethical. Therefore, it is noteworthy that in order to use this strategy it is fundamental that it be well defined for the public if the narrative is a fiction or a real fact. We also identified the main factors that led to the failure of Diletto's communication strategy using storytelling. The first one was to "sell" a fiction as if it were reality. As has been said, the stories need to be clear to the audience whether they are real or imagined. The untrue history of Diletto was told on its website and on the packaging of products as if it were the history of the company, which conveyed the idea of truthfulness to the public.

We can see this dissatisfaction with the analysis of quantitative research, in which it was presented that over $80 \%$ of the participants felt cheated to discover that the story was not true. In addition, during the focus group, one participant reportedly lost interest in consuming the company's products (unknown until then) after discovering that the story was untrue. This further reinforces that the way Diletto has led this strategy has undermined the brand's brand equity. The other factors that resulted in strategy failure were the elements used in the story. The company introduced a fictional character, a refugee from the Second War, as if it were a real person. In addition, he said that the fruits used to make ice cream were imported from 
different parts of the world. These elements influence the consumer emotionally, especially when talking about shelter.

Public dissatisfaction is perceptible, taking into account the people assessed in the focus group, when one of them says that talking about war is a "heavy" subject. Still, another participant claims to be afraid of knowing what is in the composition of the product. After all, people in the focus group agreed that if Diletto had chosen to work a fictional story, going to the fantasy side, it would be a more assertive strategy. The data presented so far will help show how Diletto's storytelling strategy has negatively impacted the brand and caused the company to lose credibility with consumers. A clear example of this is the testimony of one of the focus group participants revealing that she was a consumer and that, after discovering that the story was not true, she never again purchased the products from the ice cream maker. With this, we realize, once again, how the strategy undermined Diletto's brand equity. Finally, it is expected that the present work will contribute as a research source for students and professionals in the field of communication, who are interested in using storytelling in their branding strategies, guiding them to avoid the mistakes made by Diletto. Still, it is believed that it can serve as the basis for the creation of new stories capable of being social influencers, always structured in ethics, valuing the advertising companies and respecting their consumers.

\section{ANEXOS}

\section{Anexo 1 - História da Diletto LA FELICITÀ È UN GELATO}

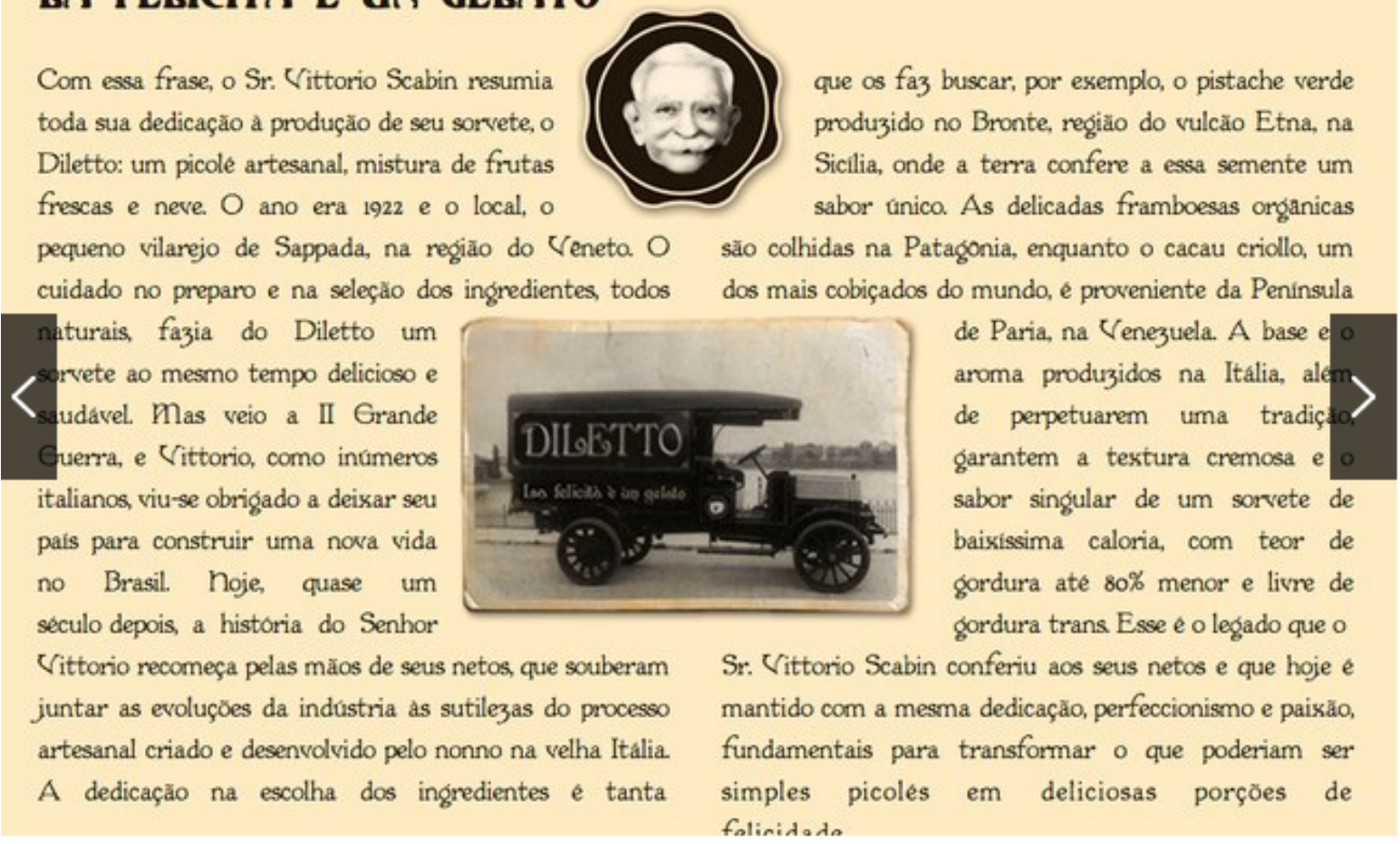

Figura disponibilizada no site da Diletto até 2014, antes da repercursão do caso envolvendo o storytelling.

Fonte: http://g1.globo.com/economia/midia-e-marketing/noticia/2014/11/historiascontadas-pelas-marcas-diletto-e-do-bem-vao-parar-no-conar.html

\section{APPENDICES}

\section{Appendix 1 - Roadmap for the implementation of the focus group}

- Does the way a brand and its products appear in the media influence your purchasing decision?

- What is your opinion when a brand tells stories to present itself or bring its products 
closer to consumers?

- Considering two identical products (X and $Y$ ), of the same price, where X knows the brand and $\mathrm{Y}$ you know the brand and they told you that it was manufactured by a gentleman who sought the raw material in a lady's yard Eventually became his wife. Which of the two would you choose? Because?

- And if I said that this story is not real, how would you feel?

- Would you continue to consume branded products after that?

- What if, instead of your future wife's yard, he found the raw material inside an asteroid that fell from the sky?

- Why do you accept this story more than the other?

- Consume how often?

- Can you tell me the brand story?

- Do you know that history is a lie?

[Tell the story to those who do not know]

- How did you feel when you learned the truth?

- Will you continue to buy branded products as often as you know about the lie?

- What could have been done by the brand to show that the story was a lie?

\section{Appendix 2 - Link to the focus group shoot: https://youtu.be/aIyeksGu8x0}

\section{Appendix 3 - Quantitative Research Questionnaire}

- Do you like when brands tell stories to promote their products?

- Do you believe that storytelling strategy can bring the consumer brand closer?

- Do you consume or have ever consumed Diletto brand ice cream and popsicles?

- On average, how often do you consume branded products?

- Do you know the story that Diletto told you about your brand?

- To continue the survey, please read below and learn about Diletto's history.

Diletto started with Mr. Vittorio Scabin, an Italian who was dedicated to producing a homemade popsicle with a mixture of fresh fruit and snow. With the arrival of the Second War, Mr. Vittorio took refuge in Brazil.

Almost a century later, his grandchildren continued their work with the same passion, perfectionism, and dedication. Thus, the ingredients are carefully chosen, for example the pistachio that comes from Sicily and the raspberries that are harvested in Patagonia.

However, the above story is not true. It was created as a marketing strategy to promote the brand and add value to its products.

- Did you feel cheated to find out that the brand story was not true?

- Has story counted influenced or influenced the way you consume the products or see the brand?

- Even if you know the story is not true, have you continued or will you continue to buy branded products?

- In your perception, has the brand lost credibility after telling this story?

- Socioeconomic Questionnaire: schooling, age and monthly income 